\title{
INTELITERM: In search of efficient terminology lookup tools for translators
}

\begin{abstract}
There is currently a pressing need to develop specific applications for translators as final users, with the purpose of fulfilling their particular professional requirements. Corpora and advanced lookup options bring benefits to translation and open up a wealth of opportunities in research. This paper presents Inteliterm, an innovative and integrated tool which combines corpus management tools with different types of searches and customisation options in order to enhance translation results and minimise translators' efforts when searching for terminology. Section 1 provides a brief foreground glimpse of the project rationale. Section 2 delves into the comprehension assistants developed in the 90's as a first step towards present-day intelligent dictionaries. Section 3 provides the theoretical foundation of the novel tool Inteliterm. Beside its proactive translation support functions, this web application also provides a TBX (TermBase eXchange) termbase editor, which allows users to create, edit or upload terminological databases in the standard-format TBX (ISO 30042: 2008) and to query their own databases using the Inteliterm tool. Users' responses and assessment of the tool are also provided in Section 4. Finally, Section 5 includes some concluding remarks with suggestions for further improvements.
\end{abstract}

Keywords: terminology lookup, translation, corpus management, term management, e-resource, next-generation intelligent dictionary.

\section{Introduction}

There is a pressing need to develop new tools that meet translators' needs satisfactorily (Bowker/Corpas 2015). Terminology resources face serious limitations as regards their typology, coverage, functionalities and degree of

Gloria Corpas Pastor: Universidad de Málaga, address, phone, fax, email Isabel Durán Muñoz: Universidad de Málaga, address, phone, fax, email 
translators' satisfaction (cf. Durán-Muñoz 2010). Against this background, this section presents Inteliterm ${ }^{1}$, an integrated and advanced corpus-management and lookup tool. This novel software application has been developed as a suitable and productive tool for professional translators, bearing in mind their different needs and expectations.

Inteliterm follows De Schryver's proposal (2009) of building flexible and intelligent dictionaries that would be able to "study and understand its users". Thus, it is a dynamic and functional electronic dictionary aimed at assisting translators when understanding the source text and producing the target text in innovative ways, mainly concerning customisation and access possibilities (cf. Bergenholtz 2011, Spohr 2011, Tarp 2011). As such, the result is a multilingual terminology resource in the domain of health and beauty tourism and is aimed at translators as potential end users.

\section{The core: intelligent dictionaries}

The first applications that could be considered "intelligent dictionaries" are the so-called comprehension assistants (assistants for decoding/understanding a foreign language), which emerged in the 1990s. These tools were intended to facilitate the understanding and decoding of a message written in another language by users with little to no knowledge of that language, in addition to streamlining the lookup of the meaning of words in the text without the need to consult other external sources. At the beginning, they appeared as an alternative to machine translation so as to remedy the frequent shortcomings and errors committed by this type of translation. They also presented themselves as more flexible and agile tools than conventional dictionaries.

Unlike dictionaries and other resources, either electronic or paper-based, which require the insertion or selection of words in the terminological resource, these applications allow the looking up of information (equivalents,

\footnotetext{
1 This application has been designed and developed within the framework of the Spanish R\&D project INTELITERM: Sistema inteligente de gestión terminológica para traductores [INTELITERM: Intelligent Terminology Management System for Translators] (ref. no. FFI2012-38881, 2012-2016). It is a multilingual tool (Spanish, English, German and Italian). for the domain of health and beauty tourism, but could be extended to other language combinations and specialised domains. It has also been partially supported by the Spanish Ministry of Economy and Competitiveness (grant no. FFI2016-75831P) and the Andalusian Regional Government (grant no. HUM2754).
} 
mainly) directly by clicking on the desired words in the working text. These tools have been developed within computational linguistics and natural language processing projects and, thus, they have frequently employed premade sources of information as resources, such as WordNet ${ }^{2}$, and do not have specific user groups in mind but general public as well as general language. As a way of example, we can mention some tools of this kind, such as the prototype COMPASS (Feldweg/Breidt 1996), which was the first one in the series of comprehension assistants to have been developed in recent decades. Newer and more complete versions of these assistants have been called "intelligent dictionaries", such as Sharp Intelligent Dictionary (SID) (Whitelock/Edmonds 2000), Intelligent Dictionary Help System (IDHS) (Agirre et al. 2003), MobiMouse Plus (Prószéky/Földes 2005: 2), Smarty (Arnaudov/Mitkov 2008) and Dixio ${ }^{3}$.

Although intelligent dictionaries represent a step forward compared to the rest of the resources that pursue a similar end, the fact is that they have relatively limited value due to their coverage of language and users, that is - as already mentioned - general language and unskilled users, respectively. In fact, the intelligent dictionaries aforementioned only present more or less sophisticated functions for textual disambiguation, usually for a limited number of language pairs and general language. To the best of our knowledge, even the most advanced ones, such as Smarty, are not "suitable" for other register-specific uses and, therefore, are far from fulfilling translators and interpreters' needs working in a specialised domain. They also do not include other features that could alleviate their lack of specialisation, such as the insertion of new databases, (conventional or ad hoc) glossaries, external searches or corpus management tools. These and other limitations make current intelligent dictionaries unsuitable for specialised communication and translation.

Some other attempts have also been carried out so far: Terminator, within the Evroterm project ${ }^{4}$ (Željko 2009), and Trandix (Durán-Muñoz 2014, DuránMuñoz/Fernández Sola 2014). These applications represent a step forward;

2 [<https://wordnet.princeton.edu/>; last access: May, 15 $\left.{ }^{\text {th }}, 2017\right]$

3 This application is commercial and can be acquired at the online shop: [<http://shop.dixio.com/en/>; last access: May, 15 $\left.{ }^{\text {th }}, 2017\right]$, where there is also a demo version available.

4 The Evroterm project's purpose is to develop a multilingual terminology database in 15 languages (although most of the equivalents are only in English and Slovenian) that would support translators from the Slovenian Unit of Translation Government Office for European Affairs (GOEA) of the Republic of Slovenia during the process of translating the European Union documentation, prior to joining the institution. 
they have been developed as a more sophisticated application aimed at translators and based on a specialised domain. Terminator is a terminological analyser (or what has been considered until now a comprehension assistant or intelligent dictionary) where the user can enter a text (written in English, German, French or Slovenian), and the application, once the text is processed, marks with hyperlinks the terms found in the Evroterm database (EDB). This application has a very simple and intuitive interface, making it easy to use by potential users.

The Union is founded on the values of respect for human dignity, freedom, democracy, equality, the rule of law and respect for human rights, including the rights of persons belonging to minorities. These values are common to the Member States in a society in which pluralism, non-discrimination, tolerance, justice, solidarity and equality between women and men prevail.'

Figure 1. Terminological analysis by Terminator

As can be seen in Figure 1, many terms from the working text are marked, allowing users to quickly and easily consult the terminological information about those terms included in the EDB. Given the context in which the tool was developed (the translation of the minutes of the European Union for the inclusion of Slovenia in the European institution), the predominant terminology relates to legislation developed within the European Union and includes mainly equivalents for the Slovenian-English combination. However, this tool has some drawbacks that hinder efficient and effective use by translators, such as the limited amount of information included in the database (only context, equivalent and, in some cases, definitions) and the lack of flexible and updated information.

Trandix is a multilingual terminological resource (Spanish, English and German) focused on the domain of adventure tourism and with translators as prospective end users. As with Terminator, Trandix facilitates the search in context by highlighting the terms included in the internal database of a working text, but it also permits the customisation of terminological entries and other features, and allows users to launch searches from the application to external resources in order to extend the information found in the tool or to find information not included in the resource. Moreover, the tool also provides the opportunity to send feedback by users to the developers with the aim of communicating problems, lack of information, inconsistencies, etc. In short, the diverse search possibilities provided by Trandix, along with its other features, help speed up translators' research tasks by saving their time and 
effort, especially when forced to use and consult many different resources to find relevant information.

Despite the advantages and improvements brought by these tools, there is still the need for a comprehensive application that overcomes their shortcomings and increases their usability in translation. As discussed before, the incorporation of corpus management and other NLP tools, such as term extractors or aligners, would be of great use to ease and speed access and lookup and to provide useful pragmatic information for translators in the form of concordances.

Taking into account the needs of our end-user group, and based on the previous and successful systems - especially the Trandix tool, which was previously developed by the authors of this paper, we designed and developed a novel application, Inteliterm, which is described in more detail in the following sections.

\section{A step forward: main functionalities}

As previously stated, the purpose of this research was to develop a flexible and integrated tool which addresses users' needs in specialised communication, and more specifically professional translators. Our main objective was the design and implementation of a system whose architecture is similar to an intelligent multilingual dictionary but, at the same time, has a modular and open structure that enhances the performance of its users by means of better access, lookup and particularly results in translation tasks.

This intelligent modular system combines an efficient lookup system through several types of searches, terminology as well as corpus management tools, with the aim of covering translators' needs and reducing the fruitless time devoted to terminology research. Another important aim of this tool is to promote constant updating and improvement based on direct feedback by users.

The application is composed of three different modules, all of which offer different functionalities and customisation according to user preferences: 1) Term search; 2) Corpus management tool; and 3) Terminology management tool.

Despite its modularity, the application provides a user-friendly and intuitive interface, which makes it very easy to use. Moreover, as it is web-based, 
users can access Inteliterm from anywhere and at any time. It also permits multiple users and operational systems, including a user manual that provides information regarding all its functionalities.

The working process is very simple: basically, the user loads the working text, either in a file or copy-pasting it, and processes the text (Figure 2). During this process, which lasts only a few seconds, the uploaded text is lemmatised with TreeTagger, and the terms that are found in the health and beauty terminological database are marked with hyperlinks on the text ${ }^{5}$ (Figure 3 ). The tool automatically detects the language of the text so the marking process is more effective. At this point, the user can edit the text in the same application, copy-paste and undo as if he/she were in a text editor, and process the text as many times as needed.

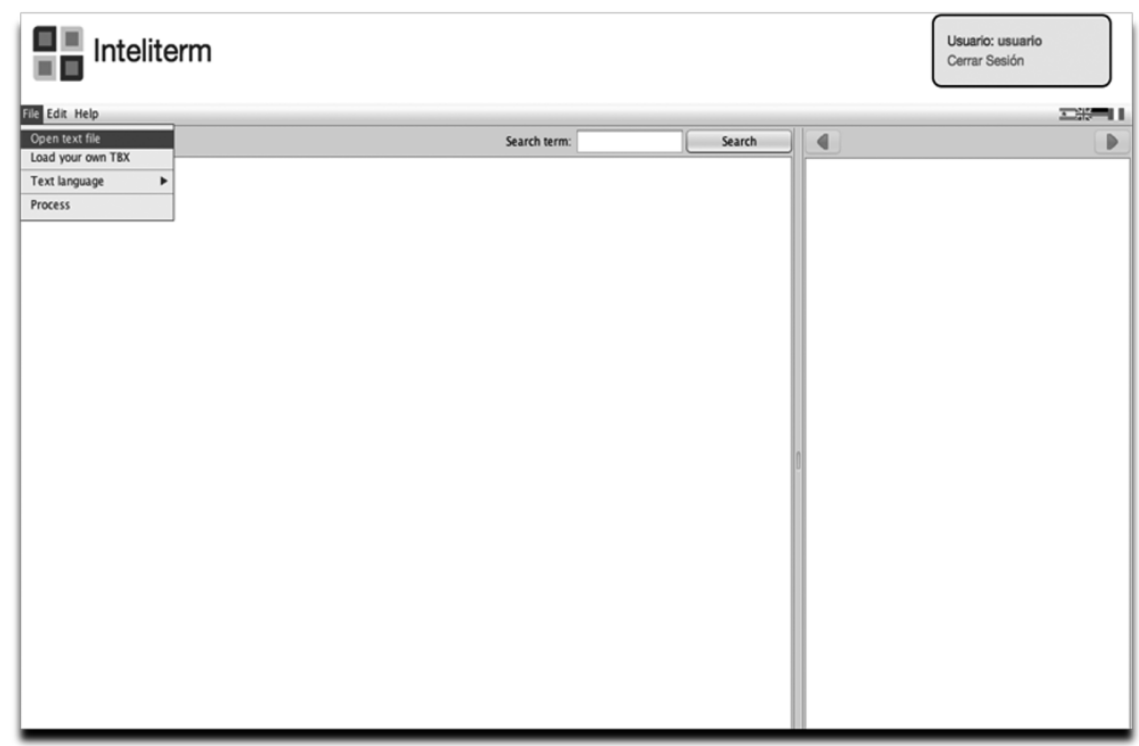

Figure 2. Loading a text file

5 As previously mentioned, the application is developed in the framework of an R\&D project concerning health and beauty terminology and, thus, the terminological database that is provided by default in the system contains terms from this domain. 


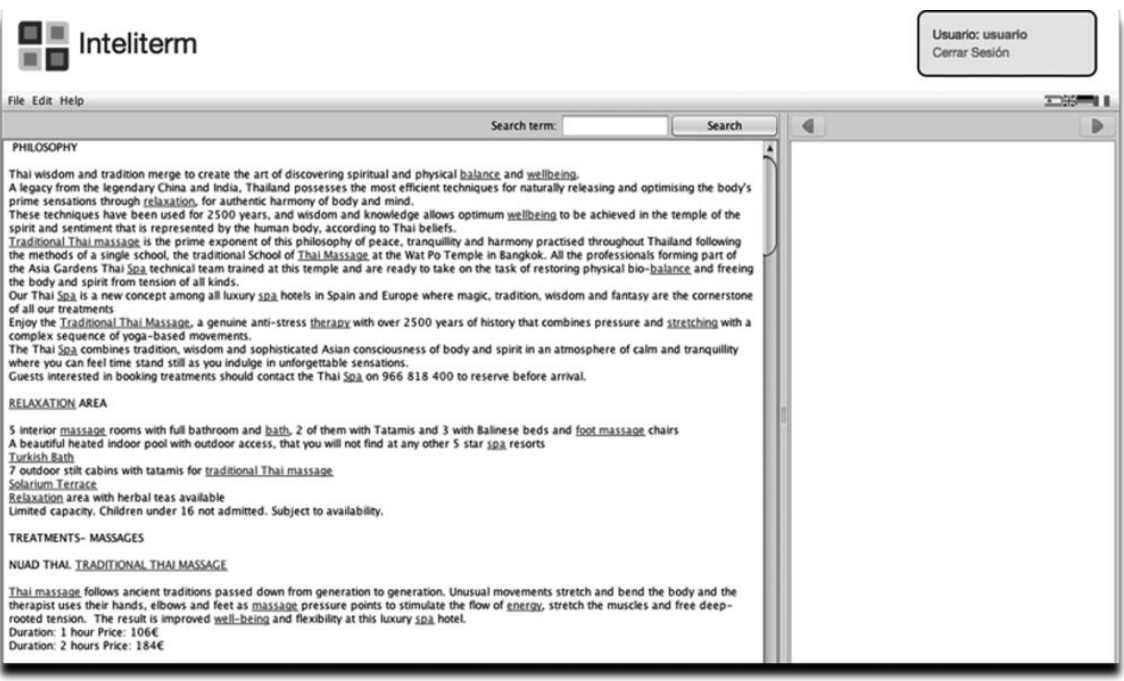

Figure 3. Terms marked with hyperlinks

Along with this first step of uploading and processing a working text, it is important to customise users' preferences (Edit > Preferences).

\begin{tabular}{|c|c|c|c|}
\hline \multirow{2}{*}{ Information sources } & \multicolumn{2}{|l|}{ Preferences } & \\
\hline & & & \\
\hline 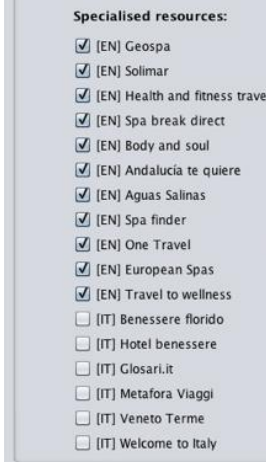 & 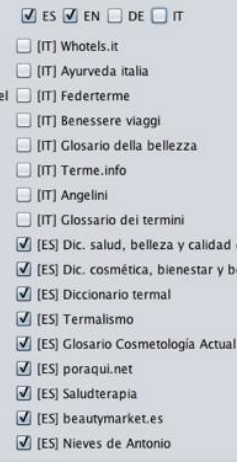 & $\begin{array}{l}\text { de vida } \\
\text { elleza }\end{array}$ & $\begin{array}{l}\square \text { [ES] elcuerpo.es } \\
\square \text { [ES] AECC } \\
\square \text { [ES] todopiscinas.es } \\
\square \text { [ES] Eroski-consumer } \\
\square \text { [ES] Termasworld } \\
\square \text { [ES] Hotel-balneario La Hermida } \\
\square \text { [DE] Die Kur } \\
\square \text { [DE] mobile massage München } \\
\square \text { [DE] Amashi massage service } \\
\square \text { [DE] Wellnessguide-München } \\
\square \text { [DE] Clossar fúr Reise und Welliness } \\
\square \text { [DE] Reise im web } \\
\square \text { [DE] Wellness-ABC } \\
\square \text { [DE] Makeupbeauty.de } \\
\square \text { [DE] Urlaub in Bad Tolz } \\
\square \text { [DE] reisen.de }\end{array}$ \\
\hline \multicolumn{2}{|l|}{ Entry fields } & \multicolumn{2}{|c|}{ "Extra } \\
\hline \multicolumn{2}{|c|}{$\begin{array}{ll}\nabla \text { Term (ES) } & \square \text { Grammatical number } \\
\nabla \text { Term (EN) } & \nabla \text { Domain } \\
\square \text { Term (DE) } & \square \text { Context } \\
\square \text { Term (In) } & \square \text { Definition } \\
\square \text { Grammatical category } & \square \text { Collocations } \\
\square \text { Gender } & \square \text { Remarks }\end{array}$} & \multicolumn{2}{|c|}{$\begin{array}{l}\square \text { Concordances } \\
\square \text { Related terms } \\
\square \text { cognates } \\
\square \text { ES } \square \text { EN } \square \text { DE } \square \pi \\
\square \text { N-grams } \\
\square \text { Parallel texts }\end{array}$} \\
\hline
\end{tabular}

Figure 4. Customising users' preferences 
With this option, the user can select the information that will be displayed in the terminological entry, together with all the different functionalities that will be available in the tool (concordances, related terms, cognates, n-grams, and parallel texts) and the external resources and the languages that will be considered in carrying out external searches (below).

In the following sections, we describe each of the three modules and their main features in more detail.

\subsection{Term search}

In order to aid access and efficient lookup for terminological information, this application offers four different types of terminology lookup to meet users' needs by minimising their effort when searching for terms.

Search in Context is one of the novel types of searches offered in the tool. It is performed by double-clicking on any of the hyperlinks marked in the working text (Figure 3 above). Once clicked, the information contained in the terminological database regarding the terms will be automatically displayed on the right-hand side of the window in the form of a terminological entry, including the information that has been selected from the Preference option in the previous step. Consequently, users can quickly and easily access the information contained in the terminological database without leaving the application or losing sight of the working text (Figure 5).

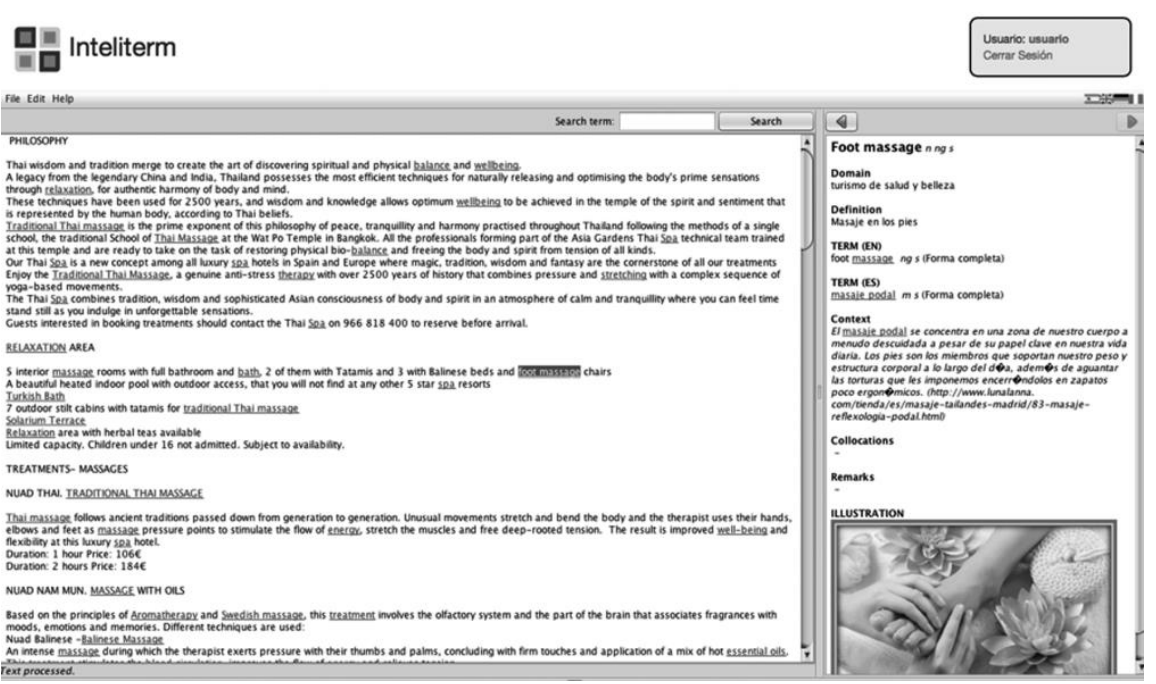

Figure 5. Terminological entry on the right side of the screen after clicking on a marked term 
A second type of search that is unique to this tool is the External Search, which consists of the possibility to launch queries to a wide range of external resources on the domain of health and beauty tourism (which are selected by the users in the Preference menu) that are linked to the application but that are external to it. To perform such searches just three simple steps are required: 1 . Select the desired word or phrase with the cursor, 2. Click on the right mouse button, and 3 . Select the desired external resource(s) from the provided list (an option to select all the available resources is also included).

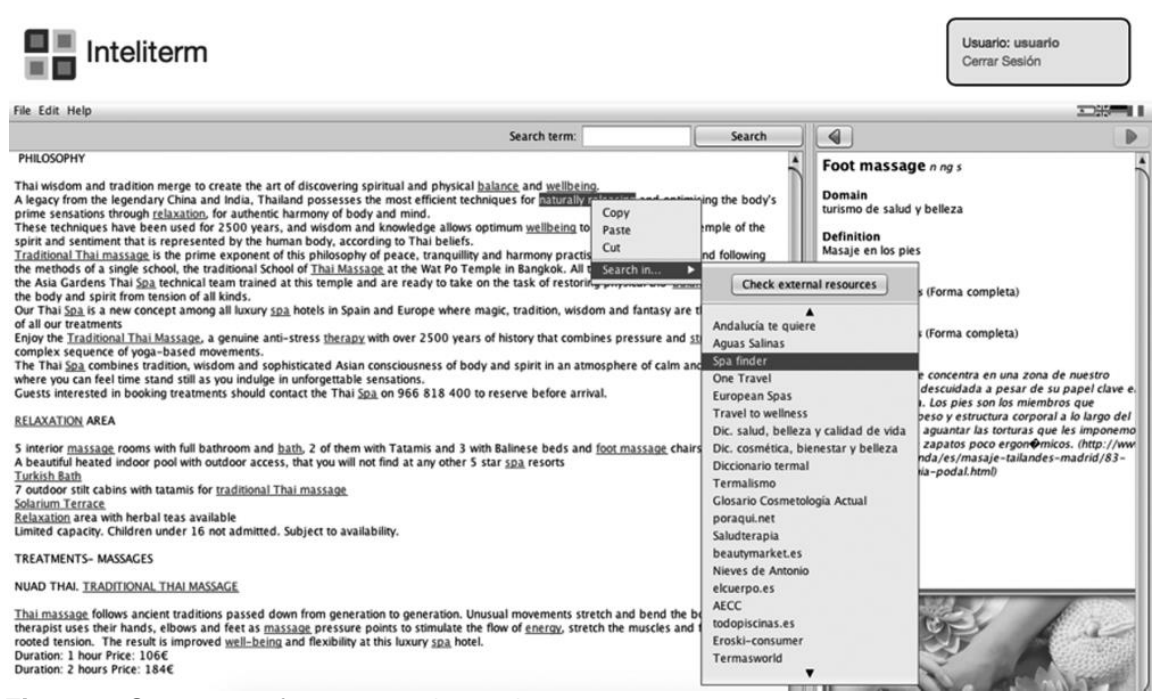

Figure 6. Steps to perform external search

Apart from these two, the application also offers other two more conventional searches: traditional searches based on terms, which consist of inserting the desired term in the search field (Figure 7); and cross-reference searches, which are based on internal hyperlinks (Figure 8).

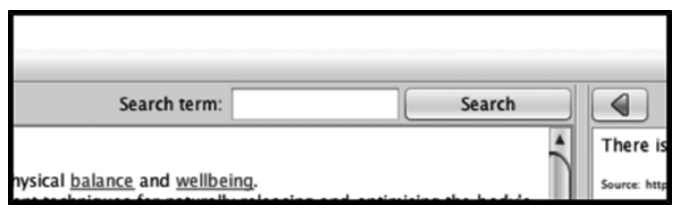

Figure 7. Search by terms 


\title{
Masaje podal $n \mathrm{~ms}$
}

\author{
Domain \\ turismo de salud y belleza \\ Definition \\ Masaje en los pies \\ TERM (DE) \\ Fußmassage $f s$ (Forma completa) \\ TERM (EN) \\ foot massage $n g s$ (Forma completa) \\ TERM (ES) \\ masaje podal $m s$ (Forma completa) \\ TERM (IT) \\ massaqqio ai piedi (Sinónimo) \\ massaquio al piede (Sinónimo) \\ massaqqio podalico $m s$ (Forma completa)
}

Figure 8. Cross-reference searches

In short, the search options included in Inteliterm aim at speeding up translators' research tasks by saving time and effort and by making these searches more productive and efficient.

\subsection{Corpus management tool}

The benefits of corpus use in translation are manifold (cf. Corpas Pastor 2001, 2004, 2008, Beeby et al. 2009, Zanettin 2012, Corpas Pastor/Seghiri 2016). Both comparable and parallel corpora offer a range of possibilities to translators that are beyond other tools and resources. Corpora enable users to consult terms in real contexts and their right and left co-texts, to check their function in a sentence and the grammatical use, to confirm abbreviations and developed forms, and to study register and style, among other uses. In its aim of filling the existing gap and providing efficient and high quality results, Inteliterm provides tools to manage two diverse but complementary corpora dealing with health and beauty tourism: one is a comparable corpus composed of original texts in the working languages (English, Spanish, German and Italian), and the other one is a parallel corpus comprising original texts and their translations.

In line with our main purpose of customisation and user-friendliness, users can select or deselect the different options offered by the application concerning corpus management in the Preference screen (Figure 9) according to their needs. 


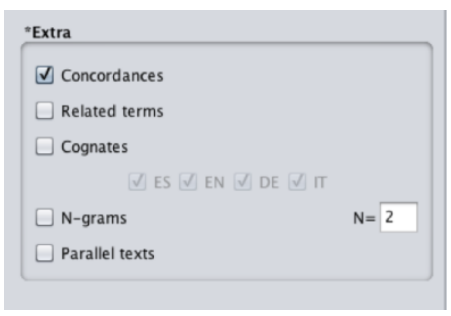

Figure 9. Options for corpus management on the bottom right corner of the Preference screen

\begin{tabular}{|c|c|c|c|c|}
\hline $\begin{array}{l}\text { Duration: } 1 \text { hour } \\
\text { Duration: } 2 \text { hour }\end{array}$ & $\begin{array}{l}\text { Price: } 106 € \\
\text { Price: } 184 €\end{array}$ & & & \\
\hline ext processed. & 17) & & & \\
\hline Concordances & Related terms & Cognates & $\mathrm{N}$-grams & Parallel texts \\
\hline
\end{tabular}

Figure 10. Options for corpus management on the bottom of the main screen

The main uses of corpora for translation are included in the application:

- Concordance searches: to search for real uses of terms and co-texts.

- Related terms: to find derivatives and other formal variations.

- Cognates: to detect equivalents that share a similar form and a common root. Users can also select their working languages.

- $\quad N$-grams: to extract terminological units formed by the selected term and $n$ units ${ }^{6}$.

- Parallel texts: to consult the parallel texts where the term in question is found.

To launch these searches, users only need to double-click on the terms they desire to consult in the working text and select the corresponding tabs in the main screen. The results are automatically displayed, together with some data regarding frequency of occurrences in the corpora.

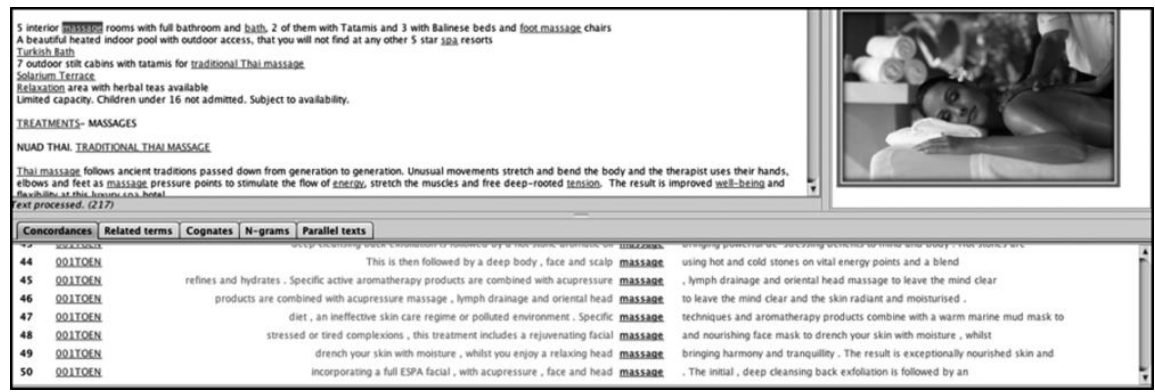

Figure 11. Concordances for the search "massage"

6 The $n$ can be also selected in the Preference screen. 


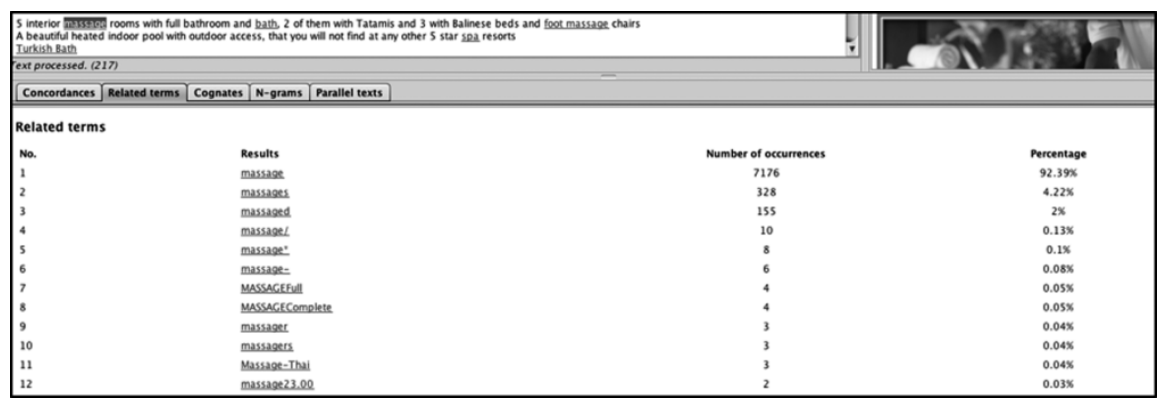

Figure 12: Related terms for the search "massage"

\begin{tabular}{|c|c|c|c|}
\hline 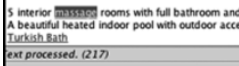 & 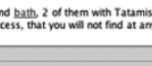 & & \\
\hline 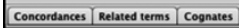 & 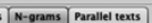 & & \\
\hline 36 & Yyctrmassises & 12 & $0.35 \times$ \\
\hline 37 & Relaxingmassage & 12 & $0.35 x$ \\
\hline 38 & sere massuge & 12 & $0.35 x$ \\
\hline 39 & sme massage & ${ }_{11}$ & $0.32 \mathrm{~K}$ \\
\hline 40 & hour massage & 11 & $0.32 x$ \\
\hline 41 & sionature massage & 11 & $0.32 \mathrm{x}$ \\
\hline 42 & neck massage & 11 & $0.32 \mathrm{x}$ \\
\hline 43 & spers massiage & 11 & $0.32 x$ \\
\hline 44 & ithing massiage & 10 & $0.29 \mathrm{x}$ \\
\hline 45 & Senes massaes & 9 & $0.26 x$ \\
\hline 46 & massaces stroter & , & $0.26 x$ \\
\hline 47 & muscle massase & 9 & $0.26 x$ \\
\hline 48 & Acomatic massage & 9 & $0.26 \mathrm{x}$ \\
\hline 49 & massage ence & 8 & $0.23 \mathrm{x}$ \\
\hline
\end{tabular}

Figure 13: N-grams for the search "massage"

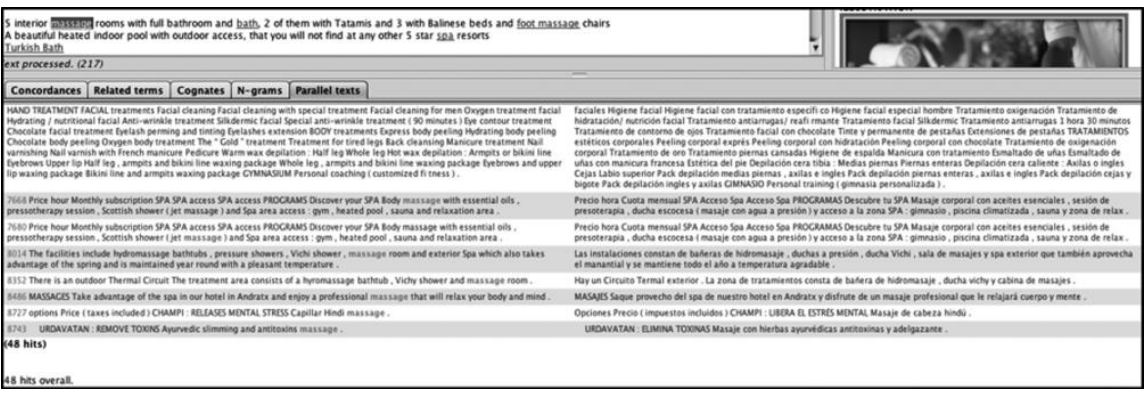

Figure 14: Parallel texts for the search "massage"

\subsection{Terminology Management Tool (TMT)}

Terminological resources, either of high or low quality, electronic or paperbased, are mostly static and unidirectional. Users cannot interact or modify the searches offered, nor the content, and they are obliged to use different applications to create their own resources that are sometimes incompatible with one another. By contrast, Inteliterm has been designed for efficient and user-friendly use. It helps reduce unproductive searches and efforts when learning how to use applications and/or employing several applications 
simultaneously. Thus, this application includes by default a database about health and beauty tourism in the working languages (English, Spanish, German and Italian), but it also offers the possibility to both enlarge this database by adding more terms and create or edit users' own databases according to their needs.

The databases can be imported or exported in the standard format TBX (TermBase eXchange) (ISO 30042: 2008), which greatly enhances the compatibility and exchange of databases among users as well as the interaction with other TBX-based applications.

Once this TMT is selected from the main page of Inteliterm (Edit > Editor), the first decision to make is the preferred option to start: 1. Load TBX, if there exists an external TBX database that can be imported in the tool; 2. New TBX, if a new TBX database is to be created; and 3. Open previous project, if the user is looking to continue working on a previous project (Figure 15). The next step is either to upload an external database, to select the previous project or to create and name a new one.

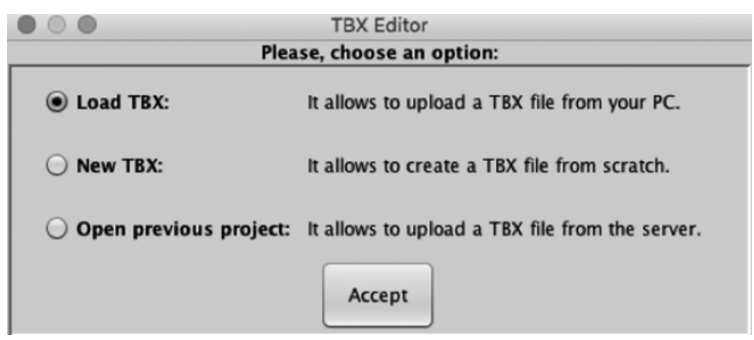

Figure 15: Working with the TBX Editor

In Figure 15, the term entry for each term is displayed. As observed, the editor interface is very intuitive and easy to use. By clicking on the New term button at the top, all the fields are unblocked and users can start adding the relevant information in the different working languages of their projects (selecting them from the given languages: English, Spanish, German and Italian). The fields that are given are those considered essential for a terminological resource aimed at translators (Durán-Muñoz 2010, 2012) ${ }^{7}$, though none of them are compulsory, apart from the Term field. Therefore, here users can also choose the information they enter in the database.

7 At this point, it is worth recalling the possibility given to users on the Preference screen to select/deselect the fields they want to have displayed in the terminological entries when using Inteliterm during their translation task. 


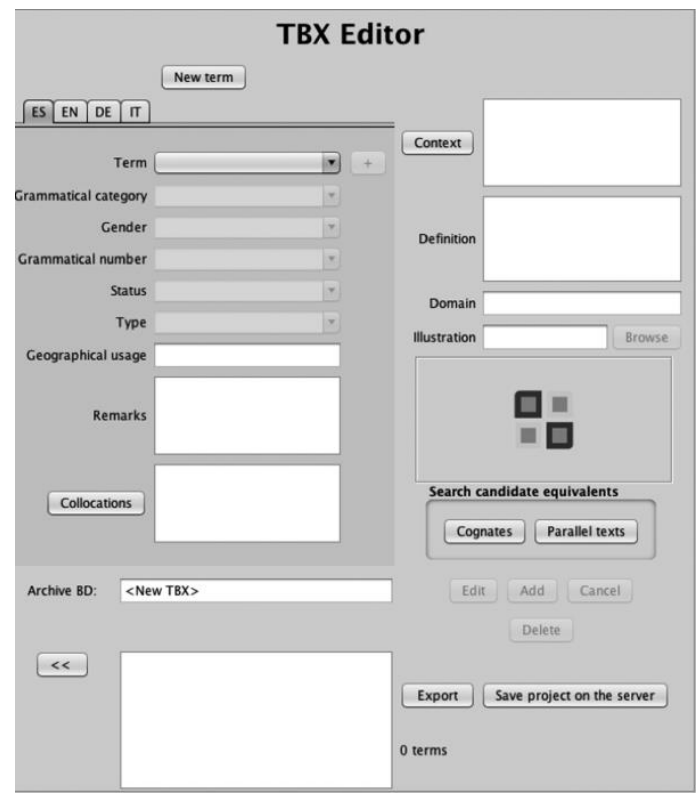

Figure 16. Term entry in the TBX Editor

When editing a database, the number of terms comprising the database is shown at the bottom. In Figure 16, the number is zero, since the database is a new creation.

Among these fields, there are some that merit further description: Collocations, Context, Illustration, and the options to Search candidate equivalents.

Collocations and Context give the opportunity to query the comparable corpus linked to the editor. By clicking on their respective buttons, a new screen displaying the information related to the term in question is provided, either in the form of a list of $n$-grams (Figure 17) or concordance lines (Figure 18). Users only need to select the correct results and the information is automatically added to the corresponding field. 


\begin{tabular}{|c|c|c|c|c|}
\hline \multicolumn{5}{|c|}{$\mathrm{N}$-grams } \\
\hline No. & Results & Number of occurrences & Percentage & \\
\hline 1 & masaje corporal & 24 & $5.62 \%$ & \\
\hline 2 & masaje suave & 19 & $4.45 \%$ & \\
\hline 3 & un masaje & 17 & $3.98 \%$ & \\
\hline 4 & masaje manual & 16 & $3.75 \%$ & \\
\hline 5 & masaje facial & 14 & $3.28 \%$ & \\
\hline 6 & masaje de & 12 & $2.81 \%$ & \\
\hline 7 & masaje tradicional & 12 & $2.81 \%$ & \\
\hline 8 & masaie relajante & 12 & $2.81 \%$ & \\
\hline 9 & masaje sueco & 10 & $2.34 \%$ & \\
\hline 10 & masaje especifice & 9 & $2.11 \%$ & \\
\hline 11 & $\underline{1 \times \text { masaie }}$ & 8 & $1.87 \%$ & \\
\hline 12 & masaje general & 7 & $1.64 \%$ & \\
\hline 13 & masaie holistice & 6 & $1.41 \%$ & \\
\hline 14 & Este masaje & 6 & $1.41 \%$ & \\
\hline 15 & masaje anticelulitico & 6 & $1.41 \%$ & \\
\hline 16 & masaje japonés & 5 & $1.17 \%$ & \\
\hline 17 & masaje craneal & 5 & $1.17 \%$ & \\
\hline 18 & El masaje & 5 & $1.17 \%$ & \\
\hline 19 & masaje drenante & 5 & $1.17 \%$ & \\
\hline 20 & masaje con & 5 & $1.17 \%$ & t. \\
\hline & & context & & \\
\hline
\end{tabular}

Figure 17. N-grams for the term "masaje"

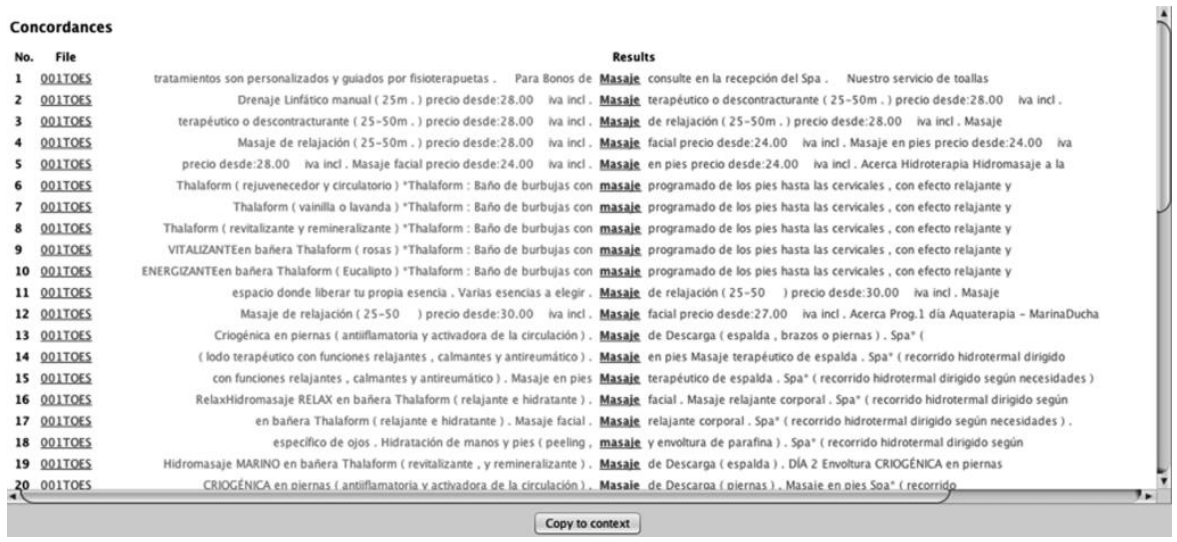

Figure 18. Concordance lines for the term "masaje"

These options enable the combination of corpus and terminological management tools and bring together the advantages of both, increasing the quality of the final results by employing real texts and reducing users' efforts by implementing Natural Language Processing tools.

The Search candidate equivalents options, instead of querying the comparable corpus, offer the possibility to consult parallel corpora, i.e. original texts and their translations. Cognates and Parallel texts provide users with access to already translated material and help them find equivalents and, if 
needed, pragmatic information for the Remarks field. Users only need to click on the respective buttons to obtain information regarding these options either in the form of a list or bilingual concordance lines.

Finally, the Illustration field allows users to upload an image to complete the description of the term being investigated. Many scholars highlight the advantages of adding descriptive images to term entries (Prieto Velasco/Tercedor Sánchez 2014, Tercedor Sánchez/López Rodríguez 2012, among others), since they clarify concepts and help to better grasp definitions. The Inteliterm TBX Editor, bearing this in mind, provides this possibility by just clicking on the Browse option and selecting the desired image.

When the term entry is completed, users will add it to their database and it will be included in the blank field at the bottom of the screen, where it will be always available to be edited or deleted in the future. As a final step, users are also able to export the terminological database in .tbx format so that it can be used in other applications, such as translation memories or other terminology management tools. In a similar way, users can also select their databases to be queried in the Inteliterm searches and, thus, substitute the default database included in the system for a new one dealing with the same or other specialised domain.

\section{User evaluation and feedback}

To prove the functionalities of Inteliterm and learn about users' satisfaction regarding the tool, we conducted an empirical experiment with students of the Degree of Translation and Interpreting at several Spanish universities (University of Málaga, University of Alcalá and University of Castilla-La Mancha) during the second semester of the academic year 2016-17. The total number of participants was 167 .

Sessions were organised as showcases in order to explain the functionalities of the tool, and time was allotted for the participants to explore the tool by themselves and to give their opinions by means of a questionnaire (Annex 1).

In general, it can be stated that the results regarding users' satisfaction were very positive, since participants conveyed their satisfaction and willingness to use Inteliterm in all sessions. The idea of developing Inteliterm as a webbased tool was also welcomed by the participants, since the response "online dictionaries" were around $80 \%$ in all the sessions. This proves that students 
are more used to employing web resources than stand-alone applications, paper-based dictionaries or other resources.

Concerning the functionality of the tool, most participants considered that access to the tool was easy (53.85\%) or very easy (3.85\%) and only $7.69 \%$ considered it very difficult, because of the adjustments that are required by Java when using the tool for the first time. As for ease of use, most of the participants indicated that it is easy and intuitive to use (65\%).

Question 7 referred to the usefulness of Inteliterm in their daily life as a translator, and more than $70 \%$ of participants considered it useful $(58 \%)$ or very useful (15\%), indicating they would use it for their translation tasks if it were available.

Participants were also asked to answer an open question about what they would add to the tool and what they would change. Their comments are essential for deciding on future improvements. Some of the most frequent comments and suggestions are provided below:

- The need to expand the number of specialised domains included in the application and, thus, the terminological databases related to these new domains.

- The possibility for users to upload their own comparable or parallel corpus from other domains to manage them with the tool.

- Easier access through other browsers and avoiding requiring adjustments by Java.

- Making the User Help option more visible to users as well as the different steps required to customise the tool.

- Keeping external resources updated.

Finally, participants were also asked to rate their satisfaction with the tool on a scale of 1 to 10, 10 being the highest score. Judging from their answers, there is a high level of satisfaction with the tool, since more than $75 \%$ of participants graded Inteliterm as 7 or 8 . The average mark was 7.5 .

\section{Conclusion}

Inteliterm fills an existing gap in the array of resources aimed at translators. This next-generation tool helps reduce the number of unproductive terminological searches by means of contextual searches, cross searches and external searches provided. It also takes into account translators' needs 
and provides several types of consultations, easy access to terminological information and customisation options. Additionally, it offers the possibility to create, edit and exchange users' own terminological databases in a very easy way that can likewise be used for consultation. All these features, combined with a corpus management tool, bring many advantages to translation and terminological work, both with comparable and parallel corpora, and NLP applications. Inteliterm proves to be a dynamic, flexible and proactive resource that facilitates the documentary work of translators and, as a result, improves efficiency and results of the final product.

Further improvements will take into account the feedback given by the participants in the experiments a well as the necessary requirement to update external resources related to health and beauty tourism and other tourism segments. Finally, we will explore the possibility of adding a terminology extractor to the TBX Editor.

\section{Bibliography}

Agirre, Eneko/Arregi, Xabier/Artola, Xabier/Díaz De llarraza, Arantza/Sarasola, Kepa/Soroa, Aitor (2003): An Intelligent Dictionary Help System. Encyclopedia of Library and Information Sciences. New York: Taylor \& Francis.

Arnaudov, Todor/Mitkov, Ruslan (2008): Smarty - Extendable Framework for Bilingual and Multilingual Comprehension Assistants. Proceedings of the 6th International Conference on Language Resources and Evaluation, LREC'08. Marrakech, 3287-3292.

Beeby, Allison/Rodríguez Inés, Patricia/Sánchez-Gijón, Pilar (2009): Corpus use and translating: Corpus use for learning to translate and learning corpus use to translate. Amsterdam: John Benjamins.

Bergenholtz, Henning (2011): Access to and Presentation of Needs-adapted Data in Monofunctional Internet Dictionaries. In: Fuertes-Olivera, Pedro A./Bergenholtz, Henning (eds.): e-Lexicography. The Internet, Digital Initiatives and Lexicography. London and New York: Continuum, 30-53.

Bowker, Lynne/Corpas Pastor, Gloria (2015): Translation Technology. In: Mitkov, Ruslan (ed.): The Oxford Handbook of Computational Linguistics. 2nd edition. Oxford: Oxford University Press. [Online first publication].

Corpas Pastor, Gloria (2001): Compilación de un corpus ad hoc para la enseñanza de la traducción inversa. In: TRANS 5. 155-179.

Corpas Pastor, Gloria (2008): Investigar con corpus en traducción: los retos de un nuevo paradigma. Frankfurt am Main: Peter Lang. 
Corpas Pastor, Gloria/Seghiri, Míriam (2016) (eds.): Corpus-based Approaches to Translation and Interpreting. From Theory to Applications. Frankfurt am Main: Peter Lang.

De Schryver, Gilles-Maurice (2009): State-of-the-Art Software to Support Intelligent Lexicography. In: Zhu, R. (ed.): Proceedings of the International Seminar on Kangxi Dictionary \& Lexicology. Beijing: Beijing Normal University, 565-580.

Durán-Muñoz, Isabel (2010): Specialized lexicographical resources: a survey of translators' needs. In: Granger, Sylviane/Paquot, Magali (eds.): eLexicography in the 21st century: New Challenges, new applications. Proceedings of ELEX2009. Cahiers du Cental, vol. 7. Lovaine-La-Neuve: Presses Universitaires de Louvain, 55-66.

Durán-Muñoz, Isabel (2012): La ontoterminografía aplicada a la traducción: Propuesta metodológica para la elaboración de recursos terminológicos dirigidos a traductores. Studien zur romanischen Sprachwissenschaft und interkulturellen Kommunikation 80. Frankfurt, Germany/New York: Peter Lang.

Durán-Muñoz, Isabel (2014): Nuevas posibilidades de búsqueda terminológica eficiente para los traductores: la herramienta Trandix. In: Vargas Sierra, C. (ed.): TIC, trabajo colaborativo e interacción en Terminología y Traducción. Granada: Editorial Comares, 201-212.

Durán-Muñoz, Isabel/Fernández Sola, Alejandro (2014): Trandix: a proactive tool to terminological searches by translators and its assessment. In: Calvo Rigual, Cesáreo/Calvi, Maria Vittoria (eds.): MONTI. Monografías de Traducción e Interpretación 6. Valencia: Universitat de Valéncia, 115-139.

Feldweg, Helmut/Breidt, Elisabeth (1996): COMPASS. An Intelligent Dictionary System for Reading Text in a Foreign Language. In: Kiefer, Ferenc/Kiss, Gábor/Pajzs, Júlia (eds.): Papers in Computational Lexicography. COMPLEX '96. Budapest: editorial, 53-62.

Prieto Velasco, Juan Antonio/Tercedor Sánchez, Maribel (2014): The embodied nature of medical concepts: image schemas and language for pain. In: Cognitive processing 15(3), 283-296.

Prószéky, Gábor/Földes, András (2005): Between Understanding and Translating: A Context-Sensitive Comprehension Tool. In: Archive of Control Sciences 15 (4), 637-644.

Spohr, Dennis (2011): A Multi-layer Architecture for "Pluri-monofunctional" Dictionaries. In: Fuertes-Olivera, Pedro A./Bergenholtz, Hennings (eds.): e-Lexicography. The Internet, Digital Initiatives and Lexicography. London/New York: Continuum, 103-120.

Tarp, Sven (2011): Lexicographical and Other e-Tools for Consultation Purposes: Towards the Individualization of Needs satisfaction. In: Fuertes-Olivera, Pedro A./Bergenholtz, Henning (eds.): e-Lexicography. The Internet, Digital Initiatives and Lexicography. London/New York: Continuum, 54-70.

Tercedor Sánchez, Maribel/López Rodríguez, Clara Inés (2012): Access to health in an intercultural setting: the role of corpora and images in grasping term variation. In: Linguistica Antverpiensia, New Series--Themes in Translation Studies (11), 247-268. 
Whitelock, Pete/Edmonds, Philip (2000): The Sharp Intelligent Dictionary. In: Heid, Ulrich/Evert, Stefan/ Lehmann, Egbert/Rohrer, Christian (eds.). Proceedings of the Ninth EURALEX International Congress (EURALEX 2000. Stuttgart: Universität Stuttgart, 871-876.

Zanettin, Federico (2012): Translation-driven corpora: Corpus resources for descriptive and applied translation studies. Manchester: St. Jerome Publishing.

Željko, Miran (2009): Improvements of Dictionaries - Suggestions by Evroterm. Proceedings of the INFuture2009: Digital Resources and Knowledge Sharing, Zagreb (Croatia). 269-278. 


\section{ANNEX 1: Questionnaire on Inteliterm}

1. Al traducir un texto de tema general, ¿qué tipo de herramientas sueles utilizar? [What types of tools do you normally use when translating a general text?]

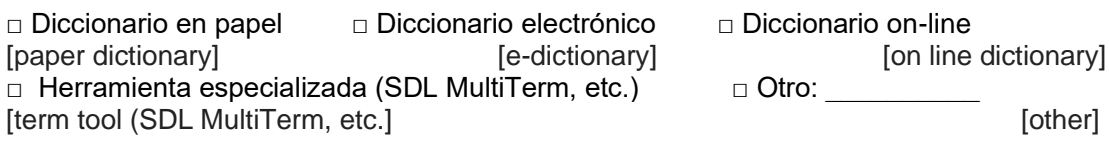

\section{2. ¿Y de tema especializado?}

[What types of tools do you normally use when translating a specialised text?]
$\square$ Diccionario en papel $\square$ Diccionario electrónico [paper dictionary] [e-dictionary] $\square$ Herramienta especializada (SDL MultiTerm, etc.)
$\square$ Diccionario on-line
$\square$ Otro: [term tool (SDL MultiTerm, etc.]

\section{3. ¿Con qué frecuencia usas herramientas de traducción asistida?} [How frequently do you use CAT tools?]

$\begin{array}{lcrr}\square \text { Siempre } & \square \text { Muchas veces } \square \text { A veces } & \square \text { Casi nunca } & \square \text { Nunca } \\ \text { [Always] } & \text { [Very frequently] } & \text { [Sometimes] } & \text { [Rarely] } \\ \text { [Never] } & & & \\ \text { Indica cuál: } & & \\ \text { [Which CAT } & \text { tools do you use?] }\end{array}$

4. Con respecto a lo que has visto de la herramienta Inteliterm, ¿crees que es fácil acceder a ella?

[After trying out Inteliterm, do you think it is easily accessible and user-friendly?]

$\begin{array}{lccc}\square \text { Muy fácil } & \square \text { Fácil } & \square \text { Un poco complicado } & \square \text { Muy difícil } \\ \text { [Very easy] } & \text { [Easy] } & {[\text { A bit complicated, difficult] }} & \text { [Very difficult] } \\ \text { Comentario: } & & \\ \text { [Comments] } & \end{array}$

\section{5. ¿Crees que es fácil de manejar?}

[Do you find Inteliterm user-friendly?]

\begin{tabular}{|c|c|c|c|}
\hline $\begin{array}{l}\text { [Very easy] } \\
\text { Comentario: }\end{array}$ & [Easy] & [A bit complicated, difficult] & [Very difficult] \\
\hline
\end{tabular}

\section{6. ¿Crees que sería útil?}

[Do you think Inteliterm could be helpful?]
$\square$ Muy útil
$\square$ Útil
$\square$ Algo útil
$\square$ Nada útil
[Very helpful]
[Hepful]
[Somewhat helpful]
[Not helpful at all]

Comentario:

[Comments]

\section{7. ¿Qué añadirías a la herramienta?}

[What else would you add to this tool?] 
8. ¿Qué cambiarías/quitarías de la herramienta?

[What would you remove from this tool?]

9. Valora del 1 al 10 la utilidad de la aplicación Inteliterm:

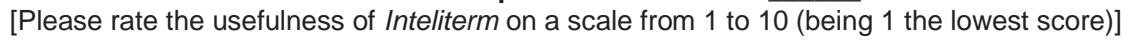

